\title{
Sub-chronic oral toxicity study of matrix tablets of micronized domperidone formulation in rodents.
}

\author{
Mohi Iqbal Mohammed Abdul ${ }^{1}$, Sabahuddin Siddique ${ }^{1,2}$, Syed Ata Ur Rahman ${ }^{1}$, Durdana Lateef ${ }^{3}$, \\ Shubhasis Dan ${ }^{4,5}$, Sourav Das ${ }^{4}$, Anirbandeep Bose ${ }^{4 *}$ \\ ${ }^{1}$ College of Pharmacy, Taibah University, Al-Madinah Al-Munawwarah, Kingdom of Saudi Arabia \\ ${ }^{2}$ Patel College of Pharmacy, Bhopal, Madhya Pradesh, India \\ ${ }^{3}$ College of Science, Taibah University, Al-Madinah Al-Munawwarah, Kingdom of Saudi Arabia \\ ${ }^{4}$ TAAB Biostudy Services, Jadavpur, Kolkata, India \\ ${ }^{5}$ Bioequivalence Study Centre, Jadavpur University, Kolkata, India
}

\begin{abstract}
The present study deals with sub-chronic oral toxicity studies in rodents of micronized domperidone matrix drug formulation. The matrix tablet of domperidone was formulated by using different polymers. After the completion of the formulation the matrix tablets the tablets were crushed into powder and a homogeneous suspension was prepared. The suspension was administered to rats at different dosages according to the study plan. During the studies animals' weight were taken at periodically. After $28^{\text {th }}$ day of study period the animal's blood was collected for pathological and biological analysis. At the termination of study, all the animals were sacrificed and vital organs were taken out for autopsy studies. After the thorough studies the results shows that that the micronized formulation did not produce any significant toxicity in rodents.
\end{abstract}

Keywords: Micronized domperidone, Matrix drug formulation, Sub-chronic oral toxicity study, Wistar strain rats. Accepted on August 20, 2018

\section{Introduction}

Toxicity study for dosage form is one of the important criterions for evaluation of safety profile of the drugs as well as novel pharmaceutical dosage forms. Acute and sub chronic toxicity studies in various species including rodents are two important tests which is used by various researchers as routine analysis $[1,2]$. Sub-chronic oral toxicity study in rodents is one of the most established and simple method to evaluate the toxicity and safety profile of any drugs and dosage forms. Researchers and scientists specifically designed sub-chronic toxicity study to perform and evaluate any drug and excipient interaction that may produce any toxic impurities. In addition sometimes micronized or nanoform of the drug also may increase the toxicity profile of the drug enormously. Regulatory bodies of various countries have also made it mandatory to evaluate toxicity studies for new drugs or novel dosage forms of old drugs also $[1,2]$.

Domperidone is one of the most effective selective dopamine D2 receptor antagonists is mainly used for antiemetic activity [3]. Literature survey reveals that domperidone may be responsible for sudden cardiac arrest [4]. Oral administration of domperidone is safe and well established but as the domperidone was micronized so there may be a possibility of enhancement of potency and toxicity [5]. In previous research work we designed a formulation which consists of micronized domperidone. The micronized domperidone was formulated in matrix dosage form. The safety profile of the dosage form must be evaluated for human use. For this reason the sub-chronic study of the dosage form in rodents was emerged as an important research component for our entire experiment to evaluate the evidence of toxicity [6-9].

\section{Materials}

48 Wistar strain rats having both male and female were purchased from IICB, Kolkata. All the animals were kept for seven days as acclimatization period before staring the experiment. Specification of the test is mentioned in Table 1.

\section{Methods}

\section{Randomization, numbering and grouping of animals}

Forty eight rats i.e. 24 male and 24 female healthy rats were divided into four groups of 6 rats per sex i.e. four dose groups receiving the dose of $0,15,30$ and $60 \mathrm{mg} / \mathrm{kg}$. Animals were 
kept for acclimation period of $7 \mathrm{~d}$ to laboratory conditions prior to the initiation of dosing. Rats were assigned to six per cage sex wise and the individual animal was fur marked with picric acid markers. The females were nulliparous and not pregnant.

Table 1. Test system of sub-chronic toxicity study in rodents.

\begin{tabular}{|c|c|}
\hline Species & Rat \\
\hline Strain & Wistar strain rats \\
\hline Source & Animal house, IICB, Kolkata \\
\hline Sex & Male and female \\
\hline Age & 6 to $8 w$ \\
\hline $\begin{array}{l}\text { No. of animals } \\
\text { per dose level }\end{array}$ & 6 per sex per dose \\
\hline Acclimation & Seven days prior to dosing \\
\hline $\begin{array}{l}\text { Identification of } \\
\text { animals }\end{array}$ & By cage number and individual marking on fur \\
\hline Diet & Pelleted feed supplied by M/s Ghosh Enterprise, Kolkata \\
\hline Water & Aquaguard pure water in glass bottles ad libitum \\
\hline Housing & $\begin{array}{l}\text { The rats were housed } 6 \text { each; of the same sex in } \\
\text { polycarbonate cages provided with bedding of husk. The } \\
\text { temperature was maintained in between } 20^{\circ} \mathrm{C} \text { to } 24^{\circ} \mathrm{C} \text { and } \\
\text { relative humidity between } 30 \% \text { to } 70 \% ; 12 \mathrm{~h} \text { each of dark and } \\
\text { light cycle was maintained. }\end{array}$ \\
\hline \multirow[t]{2}{*}{ Dose } & Male: $0,15,30$ and $60 \mathrm{mg} / \mathrm{kg}$ body weight. \\
\hline & Female: $0,15,30$ and $60 \mathrm{mg} / \mathrm{kg}$ body weight. \\
\hline $\begin{array}{l}\text { Route of } \\
\text { administration }\end{array}$ & Oral (gavages) \\
\hline
\end{tabular}

\section{Dose preparation}

The matrix tablets of domperidone were crushed into powder by mortar and pestle and then the powder was suspended in corn oil. The drug was then administered to rats at the dose levels of 15,30 and $60 \mathrm{mg} / \mathrm{kg}$ in the dose volume of $1 \mathrm{ml} / 100 \mathrm{~g}$ body weight. The domperidone tablet formulation suspensions were freshly prepared every day for $28 \mathrm{~d}$. The control animals were administered vehicle only.

\section{Observations}

Symptoms: All animals were observed daily for clinical signs. The time of onset, intensity and duration of these symptoms, if any, were recorded.

Mortality: All animals were observed twice daily for mortality during the period of the study.

Body weight: The weight of each rat was recorded on $\mathrm{d} 0$ and at weekly intervals throughout the course of the study. The group means body weights were calculated.

Food consumption: The quantity of food consumed by groups consisting of six rats each was recorded weekly and the food consumption per rat was calculated for control and dose groups.

\section{Terminal studies}

Laboratory investigations: Following laboratory investigations were carried out prior to sacrifice on completion of dosing period of $28 \mathrm{~d}$ in animal's fasted over-night. Blood samples were collected from orbital sinus following morning using heparin as anticoagulant.

Haematological investigations: Following haematological parameters were studied using Sysmax-K250 Cell Counter-Hb: Hemoglobin (g (\%)), Rt: Reticulocyte (\%), Platelets: $\left(\times 10^{5}\right.$ $\mathrm{cmm})$, WBC: White Blood Corpuscles $\left(\times 10^{3} / \mathrm{cmm}\right)$.

Biochemical investigations: Following biochemical parameters were studied using Robonik ASP-300-total serum protein (g (\%)) [10], BUN: Blood Urea Nitrogen (mg (\%)) [11], SGPT: Serum Glutamic Pyruvic Transaminase (IU/L) and SGOT: Serum Glutamic Oxaloacetic Transaminase (IU/L) according to the method described by Reitman and Frankel [12].

Necropsy: All animals were sacrificed on d 29, using $\mathrm{CO}_{2}$ asphyxiation technique (body weights mentioned in the table section are fasting body weights). Necropsy of all animals was carried out and the weights of the following organs were recorded: Liver, kidneys and heart. The organ weights were recorded as absolute values and their relative values (i.e. percent of the body weight) were calculated.

\section{Histopathology}

Following tissue samples of organs from control and animals treated at the highest dose level of $60 \mathrm{mg} / \mathrm{kg}$ were preserved in $10 \%$ formalin for histopathological examination. Adrenals; heart; kidneys; liver; lungs; stomach; adrenals, heart, kidneys, liver, lungs and stomach of low and intermediate dose group animals were preserved for possible histopathological examination, in case the histopathological examination of high dose group animals is indicative of abnormalities associated with the treatment [13-15].

\section{Statistical evaluation}

All the animals were assigned into four different treatments i.e. control, low dose, middle dose and high dose. After $28 \mathrm{~d}$ vigorous studies all pathological and biochemistry parameters had been evaluated statistically. Analysis of Variation (ANOVA) is the suitable statistical tool to compare the means of three or more groups. The test compares the variation (variance) in the mean between treatments with those within treatments. The ratio of variations (variance) in the mean between treatments with those within treatments determines the $\mathrm{F}$ value. If the $\mathrm{F}$ value for different studies found to be less than recorded $F$ value was tabulated against 2 d.f for between mean square and 45 d.f within mean square at 5\% level of significance then the results were found to be non-significant [16-18]. 


\section{Results}

\section{Sub-chronic oral toxicity study (28 d) on rats}

All the animals taking various levels of doses were free of intoxicating signs throughout the dosing period of $28 \mathrm{~d}$. The mortality and intoxication symptoms were shown in Table 2.

\section{Variation of body weight of experimental rats}

Both male and female animals from control and the different dose groups exhibited normal body weight gain throughout the dosing period of $28 \mathrm{~d}$ as illustrated in Table 3.

\section{Food consumption of experimental animals}

During the dosing period and at termination the quantity of food consumed by both male and female animals from different dose groups was found to be comparable with that of control animals which is tabulated in Table 4.

\section{Haematological investigations of blood parameters}

The hematological parameters of male and female-were analysed at termination of dosing on d 29, no significant changes were observed in the values of different parameters studied when compared with controls and values obtained were within normal biological and laboratory limits which are shown in Table 5.

The ANOVA was applied to evaluate the statistical difference of the mean hematological parameters among four independent drug treatments referring to the Table $6, F$ against 3 degree of freedom for between mean square and 44 degree of freedom for within mean square; we find a value 2.8 at $5 \%$ level of significance. Since the value for $\mathrm{F}$ obtained in the present experiment is less than the recorded value, we conclude that the difference between the treatment means is not significant $(\mathrm{p}<0.05)$.

Table 2. Effect of drug treatment on clinical signs of intoxication.

\begin{tabular}{|c|c|c|c|c|c|c|c|}
\hline \multirow[t]{2}{*}{ Group no. } & \multirow[t]{2}{*}{ Dose (mg/kg) } & \multirow[t]{2}{*}{ Observed Signs } & \multirow[t]{2}{*}{ Total no. of animals } & \multirow[t]{2}{*}{ Animal nos. } & \multicolumn{2}{|c|}{ Period of signs in days } & \multirow[t]{2}{*}{ Mortality } \\
\hline & & & & & From & To & \\
\hline \multicolumn{8}{|l|}{ Sex: Male } \\
\hline I & Control & NIL & 6 & $1-6$ & 1 & 28 & $0 / 6$ \\
\hline ॥ & 15 & & 6 & $13-18$ & 1 & 28 & $0 / 6$ \\
\hline III & 30 & & 6 & $25-31$ & 1 & 28 & $0 / 6$ \\
\hline IV & 60 & & 6 & $37-42$ & 1 & 28 & $0 / 6$ \\
\hline \multicolumn{8}{|c|}{ Sex: Female } \\
\hline I & Control & NIL & 6 & $7-12$ & 1 & 28 & $0 / 6$ \\
\hline II & 15 & & 6 & $19-24$ & 1 & 28 & $0 / 6$ \\
\hline III & 30 & & 6 & $31-36$ & 1 & 28 & $0 / 6$ \\
\hline IV & 60 & & 6 & $43-48$ & 1 & 28 & $0 / 6$ \\
\hline
\end{tabular}

Table 3. Group means body weight ( $g$ ).

\begin{tabular}{|c|c|c|c|c|c|c|c|}
\hline \multirow[t]{2}{*}{ Gr. no. } & \multirow[t]{2}{*}{ Dose (mg/kg) } & & \multicolumn{5}{|l|}{ Day } \\
\hline & & & 0 & 7 & 14 & 21 & 28 \\
\hline I & Control & Mean \pm SD & $104.23 \pm 6.62$ & $104.58 \pm 7.49$ & $105.97 \pm 8.00$ & $106.13 \pm 7.01$ & $107.18 \pm 7.37$ \\
\hline II & 15 & & $103.53 \pm 5.38$ & $104.93 \pm 5.43$ & $105.48 \pm 4.68$ & $106.43 \pm 4.34$ & $107.13 \pm 5.41$ \\
\hline III & 30 & & $105.95 \pm 5.78$ & $104.15 \pm 5.44$ & $104.92 \pm 4.93$ & $105.95 \pm 5.46$ & $106.07 \pm 5.18$ \\
\hline IV & 60 & & $103.95 \pm 5.44$ & $104.77 \pm 5.38$ & $105.35 \pm 4.81$ & $106.07 \pm 4.57$ & $106.28 \pm 5.03$ \\
\hline
\end{tabular}

\section{Biochemical investigations}

At termination on d 29, all biochemical parameters were studied i.e. total serum protein; SGPT, SGOT, BUN were found to be comparable with controls and were within the normal biological and laboratory limits (Table 7).
The ANOVA was applied to evaluate the statistical difference of the mean biochemical parameters among four independent drug treatments. Referring to the Table 8, F against 3 degree of freedom for between mean square and 44 degree of freedom for within mean square, we find a value 2.8 at $5 \%$ level of significance. Since the value for $\mathrm{F}$ obtained in the present 
experiment for different biochemical parameters is less than the recorded value, we conclude that the difference between the treatment means is not significant $(\mathrm{p}<0.05)$.

Table 4. Group mean food consumption (g/animal).

\begin{tabular}{lllllll} 
Gr. no. Dose $(\mathrm{mg} / \mathrm{kg})$ & \multicolumn{2}{l}{ Day } \\
\cline { 2 - 6 } & 0 & 7 & 14 & 21 & 28 \\
\hline
\end{tabular}

\begin{tabular}{|c|c|c|c|c|c|c|c|}
\hline I & Control & Mean & 4.86 & 5.46 & 5.94 & 6.15 & 6.49 \\
\hline II & 15 & & 5.31 & 5.98 & 5.52 & 5.86 & 6.21 \\
\hline III & 30 & & 4.94 & 5.56 & 5.84 & 5.72 & 6.09 \\
\hline IV & 60 & & 5.15 & 5.42 & 5.17 & 5.58 & 5.44 \\
\hline
\end{tabular}

Table 5. Group mean-haematology.

\begin{tabular}{|c|c|c|c|c|c|c|}
\hline Gr. no. & Dose (mg/kg) & & $\mathrm{Hb}(\mathrm{g}(\%))$ & Platelets $\left(\times 10^{5} / \mathrm{c}\right)$ & Rt (\%) & Total WBC $\left(\times 10^{3} / \mathrm{cmm}\right)$ \\
\hline I & Control & Mean \pm SD & $14.14 \pm 0.97$ & $5.58 \pm 0.84$ & $1.07 \pm 0.20$ & $7.13 \pm 0.87$ \\
\hline II & 15 & & $14.56 \pm 1.34$ & $6.02 \pm 0.71$ & $1.13 \pm 0.22$ & $7.08 \pm 0.54$ \\
\hline III & 30 & & $14.38 \pm 0.64$ & $6.03 \pm 0.84$ & $1.17 \pm 0.19$ & $7.14 \pm 0.40$ \\
\hline IV & 60 & & $14.51 \pm 0.64$ & $6.42 \pm 0.81$ & $1.23 \pm 0.23$ & $7.28 \pm 0.46$ \\
\hline
\end{tabular}

Table 6. ANOVA of Hematological parameters of 4 different groups.

\begin{tabular}{|c|c|c|c|c|c|}
\hline Parameters & No. of animals & $\begin{array}{l}\text { Mean square (Between } \\
\text { treatment) }\end{array}$ & $\begin{array}{l}\text { Mean square (Within } \\
\text { treatment) }\end{array}$ & $F$ value & Statistical significance \\
\hline Hemoglobin (g \%) & 48 & 0.4 & 0.67 & 0.61 & NS \\
\hline Platelets $\left(\times 10^{5} / \mathrm{cmm}\right)$ & 48 & 1.38 & 0.64 & 2.17 & NS \\
\hline Rt (\%) & 48 & 0.126 & 0.12 & 1.05 & NS \\
\hline Total WBC $\left(\times 10^{3} / \mathrm{cmm}\right)$ & 48 & 47 & 0.35 & 0.23 & NS \\
\hline
\end{tabular}

Table 7. Group meta-blood chemistry.

\begin{tabular}{|c|c|c|c|c|c|c|}
\hline Gr. no. & Dose (mg/kg) & & Total serum protein $(\mathbf{g}(\%))$ & BUN (mg \%) & SGPT (IU/L) & SGOT (IU/L) \\
\hline I & Control & Mean \pm SD & $6.92 \pm 0.57$ & $28.33 \pm 4.47$ & $55.25 \pm 8.14$ & $114.5 \pm 17.15$ \\
\hline II & 15 & & $7.04 \pm 0.37$ & $28.33 \pm 3.96$ & $50.01 \pm 4.39$ & $119.67 \pm 9.88$ \\
\hline III & 30 & & $6.78 \pm 0.27$ & $26.67 \pm 4.09$ & $52.5 \pm 2.81$ & $126.75 \pm 18.00$ \\
\hline IV & 60 & & $7.06 \pm 0.40$ & $26.75 \pm 2.83$ & $51.58 \pm 2.67$ & $111.92 \pm 19.44$ \\
\hline
\end{tabular}

Table 8. ANOVA of biochemical parameters of 4 different groups.

\begin{tabular}{lllll}
\hline Parameters & No. of animals & $\begin{array}{l}\text { Mean square } \\
\text { treatment) }\end{array}$ & $\begin{array}{c}\text { (Between } \\
\text { Mean square } \\
\text { treatment) }\end{array}$ & (Within F value \\
\hline Total serum protein $(\mathrm{g} \%)$ & 48 & 0.2 & 0.17 & 1.18 \\
\hline BUN (mg \%) & 48 & 15.87 & 15.12 & $\mathrm{NS}$ \\
\hline SGPT (IU/L) & 48 & 85.65 & 52.01 & 1.02 \\
\hline SGOT (IU/L) & 48 & 755.96 & 345.75 & $\mathrm{NS}$ \\
\hline
\end{tabular}

\section{Variation of organ weights}

The animals from control and the different dose groups exhibited normal organ weight after the sacrifice at $29^{\text {th }} \mathrm{d}$. The ANOVA was applied to evaluate the statistical difference of the mean weight of vital organs among four independent drug treatments (Table 9). Referring to the Table 10, F against 3 degree of freedom for between mean square and 44 degree of freedom for within mean square, we find a value 2.8 at $5 \%$ level of significance. Since the value for $F$ obtained in the present experiment for different organ weights is less than the recorded value, we conclude that the difference between the treatment means is not significant $(\mathrm{p}<0.05)$. 


\section{Necropsy}

Summary of necropsy findings in male and female animals are described in Table 11. The gross pathological examination revealed no abnormality attributable to the treatment.

Table 9. Group mean-relative values (\%) of different organ weights in different groups.

\begin{tabular}{|c|c|c|c|c|c|}
\hline Gr. no. & Dose $(\mathrm{mg} / \mathrm{kg})$ & & Liver (g) & Kidneys (g) & Heart (g) \\
\hline 1 & Control & Mean \pm SD & $3.95 \pm 0.31$ & $0.63 \pm 0.04$ & $0.43 \pm 0.06$ \\
\hline II & 15 & & $3.99 \pm 0.16$ & $0.65 \pm 0.05$ & $0.41 \pm 0.02$ \\
\hline III & 30 & & $3.87 \pm 0.33$ & $0.62 \pm 0.04$ & $0.42 \pm 0.02$ \\
\hline IV & 60 & & $4.09 \pm 0.29$ & $0.63 \pm 0.04$ & $0.43 \pm 0.04$ \\
\hline
\end{tabular}

Table 10. ANOVA of hematological parameters of 4 different groups.

\begin{tabular}{llllll}
\hline Parameters & No. of animals & Mean square (Between treatment) & Mean square (Within treatment) & F value & Statistical significance \\
\hline Liver & 48 & 0.1 & 0.08 & NS \\
\hline kidney & 48 & 0.012 & 0.01 & 1.32 & NS \\
\hline Heart & 48 & 0.086 & 0.01 & NS \\
\hline
\end{tabular}

Table 11. Summary of gross pathology findings.

\begin{tabular}{|c|c|c|c|c|}
\hline \multirow{2}{*}{$\begin{array}{l}\text { Site and lesion } \\
\text { observed }\end{array}$} & \multicolumn{4}{|c|}{ Group } \\
\hline & I & II & III & IV \\
\hline \multicolumn{5}{|c|}{ Male } \\
\hline $\begin{array}{l}\text { No abnormality } \\
\text { detected (NAD) }\end{array}$ & $1-6$ & $13-18$ & $25-30$ & $37-42$ \\
\hline \multicolumn{5}{|c|}{ Female } \\
\hline $\begin{array}{l}\text { No abnormality } \\
\text { detected (NAD) }\end{array}$ & $7-12$ & $19-24$ & $31-36$ & $43-48$ \\
\hline
\end{tabular}

\section{Histopathology of different organs of high dose groups}

Summary of histopathological observations of vital organs of different dose group is given in Table 12. Histopathological examination of animals from high dose group revealed no abnormality attributable to the treatment.

Table 12. Summary of histopathology findings of different vital organs of low and high dose.

\begin{tabular}{llll}
\hline Group & & $\mathbf{0 ~} \mathbf{~ m g} / \mathbf{k g}$ & $\mathbf{6 0 ~} \mathbf{~ g} / \mathbf{k g}$ \\
\hline No. of animals & 6 & 6 \\
\hline Adrenals & & \# SEV & \# SEV \\
\hline Heart & \# Ex & 6 & 6 \\
\hline Kidneys & \# Ex & 6 & 6 \\
\hline Liver & \# Ex & 6 & 6 \\
\hline Lungs & \# Ex & 6 & 6 \\
\hline
\end{tabular}

6=normal histopathology

\section{Discussion}

The experimental study has been performed to evaluate the potential of micronized drug domperidone to induce a systemic response after exposure. Domperidone is a very popular antiemetic drug, acts on D2 receptor with low toxicity [19]. Our experimental study is aimed to evaluate toxicity studies of micronized form of domperidone. Due to higher exposed surface area micronized form of domperidone is considered to have better oral absorption. Sub-chronic toxicity studies were executed to investigate any overall short-term toxicity produced by the micronized form of the drug due altered bioavailability.

The study animals of either sex were found alive, no significant alteration of body weight was noticed. Food consumption of the entire study group was found to be normal that indicates domperidone didn't change the appetite of the treated rodents.

Evaluation of hematological profile was performed, and hence any significant change with reference was not found. However, drug induced change in hematology indicates a number of possible serious or life threatening health hazards in individuals.

Domperidone pass through an extensive first-pass metabolism in the liver so different serum protein and enzyme was determined and treatment groups were compared with control group as a biochemical marker to investigate any hepatotoxicity. The obtained result was found to be satisfactory, and no significant alteration in serum protein and enzymes (i.e. SGOT, SCPT) were noticed. Urea is a metabolic waste product produced during metabolism, excreted after filtration in kidney and is used as a surrogate marker for identifying renal toxicity [20-22]. The serum concentration of BUN was found within normal range throughout the $28 \mathrm{~d}$ study period.

The organ weights of all the study animals of either sex was determined and compared after post study sacrifice of animal, no marked alteration was observed in statistical comparative values.

The entire study shows a promising result that micronized domperidone when formulated in matrix tablet did not produce any significant toxicity. Previous research work shows some 
toxicity but the micronized form of domperidone matrix tablet formulation did not produce any major toxicity.

\section{Conclusion}

Sub chronic oral toxicity is generally used to find any short term or long term toxicity induced by the use of the drug. Domperidone is a drug of highly water insoluble in nature. As a result the bioavailability of domperidone formulation is also compromised in conventional dosage form. To overcome this problem we have developed a novel sustained release dosage form using domperidone in micronised form.

After development of matrix tablet formulation, there was a need to evaluate their in-vivo performance in healthy human volunteers. So prior to this, a preclinical sub-chronic oral toxicity study of the final formulation was carried out in rats to see for any toxic effects due to pharmacological interaction between the drugs and the excipients as well as the effects of the micronized particles of domperidone in formulation. Subchronic toxicity showed no significant abnormality in haematological parameters, biochemical parameters, organ weights and histopathology findings.

\section{References}

1. Organization of Economic Co-operation and Development (OECD). The OECD Guideline for Testing of Chemicals: 423 Acute Oral Toxicity-Acute Toxic Class Method, OECD, Paris, France 2001.

2. Organization of Economic Co-operation and Development (OECD). The OECD Guideline for Testing of Chemicals: 408 Subchronic Oral Toxicity-Rodent: 90 Day Study, OECD, Paris, France 1998.

3. Pasricha PJ. Prokinetic agents, antiemetics agents used in irritable bowel syndrome. The pharmacological basis of therapeutics (10th Edn.). New York, McGraw Hill Book Inc. $2001 ; 1021$.

4. Domperidone maleate-association with serious abnormal heart rhythms and sudden death (cardiac arrest)-for health professionals. Ottawa (ON): Health Canada; 2012.

5. Vaughan CJ, Aherne AM, Lane E. Identification and regional distribution of the dopamine $\mathrm{D}(1 \mathrm{~A})$ receptor in the gastrointestinal tract. Am J Physiol Hegul Integr Comp Physiol 2000; 279: 599-609.

6. Gad GSC, Chengelis CP. Acute toxicology program: study design and development. Acute Toxicology Testing (2nd Edn.). Elsevier Inc. 1998; 17-30.

7. Chang CJ. Acute and $28 \mathrm{~d}$ subchronic oral toxicity of an ethanol extract of Zingiber zerumbet (L.) Smith in rodents. Evid Bas Compl Alt Med 2012; 1-11.

8. Dar SA. Acute and sub-acute oral toxicity studies of Deedan-A Unani drug in Albino rats. J Appl Pharm Sci 2015; 5: 107-114.

9. Steven KR, Mylecrdfaine L. Issues in chronic toxicology. Principles and Methods of Toxicology (3rd Edn.). New York: Ravan Press 1994; 673.
10. Wauquier A, Niemegeers CJE, Janssen PAJ. Jpn J Pharmacol 1981; 31: 305.

11. Reitman S, Frankel S. A colorimetric method for the determination of serum glutamic oxaloacetic and glutamic pyruvic transaminase. Am J Clin Pathol 1957; 28: 56-63.

12. Henry RJ, Cannon DC, Winkelman JW. Clinical chemistry, principles and techniques, (2nd Edn.). Harper and Row: New York 1974.

13. Ramaiah SK. Preclinical safety assessment: current gaps, challenges, and approaches in identifying translatable biomarkers of drug-induce liver injury. Clin Lab Med 2011; 31: 161-172.

14. Dybing E, Doe J, Groten J, Kleiner J, OBrien J. Hazard characterization of chemicals in food and diet: dose response, mechanism and extrapolation issues. Food Chem Toxicol 2002; 42: 237-282.

15. Raza M, Al-Shabanah OA, El-Hadiyah TM, Al-Majed AA. Effect of prolonged vigabatrin treatment on hematological and biochemical parameters in plasma, liver and kidney of Swiss albino mice. Sci Pharm 2002; 70: 135-145.

16. Scharer K. The effect of chronic underfeeding on organ weights of rats. How to interpret organ weight changes in cases of marked growth retardation in toxicity tests? Toxicology 1977; 7: 45-56.

17. Sellers RS, Mortan D, Michael B, Roome N Johnson JK, Yano BL, Perry R, Schafer K. Society of toxicologic pathology position paper: organ weight recommendations for toxicology studies. Toxicol Pathol 2007; 35: 751-755.

18. Yamthe LR, David K, Ngadena YM. Acute and chronic toxicity studies of the aqueous and ethanol leaf extracts of Carica papaya Linn in Wistar rats. J Nat Prod Plant Resour 2012; 2: 617-627.

19. Traynor J, Geddes CC, Fox JG. How to measure renal function in clinical practice. Br Med J 2006; 333:733-737.

20. Zepeda RJ, Candiracci M, Lobos N, Lux S, Miranda HF. Chronic toxicity study of neosaxitoxin in rats. Mar Drugs 2014; 12: 5055-5071.

21. Perrone R, Madias N, Levy A. Serum creatinine as an index of renal function: New insights into old concepts. Clin Chem 1992; 38:1933-1953.

22. Kaplan A. The determination of urea, ammonia and urea, in Methods of biochemical analysis. California: John Wiley and Sons 2006.

\section{*Correspondence to}

Anirbandeep Bose

TAAB Biostudy Services

Jadavpur, Kolkata

India 